\title{
The Co-construction of Mine Villages-an Important Way for Coal Mining Enterprises in Yunnan's Minority Areas to Fulfill Social Responsibility
}

\author{
Yunhong GONG \\ Qujing Normal University, \\ Qujing, Yunnan Province, 655011 China
}

\begin{abstract}
In the minority areas with the backward development of economy, the fulfillment of social responsibility by coal mining enterprises is of more important significance. The coal mining enterprises in minority areas should pay more attention to the social responsibility with the local minority characteristics, mainly including maintaining the national unity, promoting the prosperity and development, and protecting the ecological environment in minority areas, etc. In recent years, explorations on a model for the co-construction of mine villages in many places of Yunnan province are worthy of reference and introduction. Therefore, the co-construction of mine villages is necessarily used as an important way for the coal mining enterprises in Yunnan's minority areas to fulfill social responsibility.
\end{abstract}

Keywords: The Co-construction of Mine Villages; Minority Areas; Coal Mining Enterprises; Social Responsibility

\section{Introduction}

Ethnic minority areas are rich in coal resources, and coal mining is often the most important industry in these areas and also one of the industries mainly providing labor employment. For the minority areas with the backward development of economy, the fulfillment of social responsibility by coal mining enterprises is of more important significance. In minority areas, necessary funding is in the greatest shortage, and infrastructure construction and management services are hysteretic, while the coal mining enterprises possess a capital advantage and the management personnel who are good at economic situation, planning, and innovation. Therefore, the coal mining enterprises must be encouraged and supported to fulfill their social responsibility and obligations, and give full play to the advantages in capital, awareness in talents and development, and management ideas, etc. Specifically, these enterprises can help collaborative villages know well the development ideas, make work measures, make every effort to the co-development of social undertakings and the co-construction of infrastructure, actively undertake poverty alleviation work, and participate in social construction and management by combining with their own development characteristics and the actual needs of the collaborative villages. In recent years, explorations on a model for the co-construction of mine villages in many places of Yunnan province are worthy of reference and introduction. Therefore, the co-construction of mine villages is necessarily used as an important way for the coal mining enterprises in Yunnan's minority areas to fulfill social responsibility.

\section{The intension of the corporate social responsibilities of the coal mining enterprises in minority areas}

In a general sense, the social responsibilities necessary for an enterprise to fulfill include economic responsibility, legal responsibility, ethical responsibility, environmental responsibility, charity responsibility, etc. The indexes of the corporate social responsibility in 
different industry have characteristics of their own industry, that is, the contents of a social responsibility are different based on the industrial characteristics, and some regional characteristics are necessarily considered by the enterprises in minority areas. For the coal mining enterprises in minority areas, they are necessary to focus on the social responsibilities with special regional minority characteristics in addition to performing the social responsibility in a broad sense.

Performing the social responsibility can help maintain the national unity. Coal mining has been a labor-intensive industry in which huge numbers of labors are employed in China. The great minority population has become the main force of extracting coal resources in minority areas. However, some coal mining enterprises don't consider their social responsibilities for pure pursuit of profit and economic efficiency so that harmonious circumstances affecting the minority relations have emerged. In the minority areas with the backward development of the economy, coal mine is not only an important industry for the local labor employment and local government finance income, but also the main source of a miner family's life. Along with the development of resources, the social problems that can't be ignored are caused along with the development of the economy. For example, the geological hazards induced by mining are increasingly prominent, and the economic development of the mining industry divorces from the income increase of the mass peoples in diggings, so that ore cluster conflicts have been triggered.

Performing the social responsibility can help protect the ecological environment in minority areas. The environment of the coal mines in minority areas is stable and harmonious before the development of coal resources, but the frequently intense human activities have made the surrounding environment greatly changed after the development and construction, because some human landscapes such as local landscape sceneries, historical sites, and nature reserves in minority areas are affected by the mining of coal resources. Simultaneously, a series of other environmental problems, such as ground surface subsidence, farmland aridity, village migration, buildings damage, land desertification, gangue accumulation, surface water flow reduction, drying groundwater water-supply source, and hazardous substances flowing into the underground water system, etc.

\section{The co-construction of mine villages is an important way for the coal mining enterprises in minority areas to fulfill social responsibilities}

The co-construction of mine villages is to unite coal mining enterprises, villages' grass-root organizations, and the mass people into an interest community under the guidance of the government, and build a resource-conserving "co-construction mechanism", environmental friendly "co-protection mechanism", and development result "co-sharing mechanism".

\subsection{The co-construction of mine villages promotes the coal mining enterprises in minority areas to better fulfill the social responsibility of maintaining the national unity}

The "co-construction mechanism" for the co-construction of mine villages connects the interests of the enterprises and the mass people around coal mines closely together, and thus, the rights and interests of the people in minority areas are better safeguarded.

In Fuyuan County of Yunnan, a connected support responsibility system has been implemented, in which the coal mining enterprises are mobilized to connect together based on the "one-to-one" support model and help a natural village or a village committee according to the actual business management situation, so as to help the people in poverty villages solve the survival and development problems. Since 2007, the coal mining 
enterprises in the country had donated 290 million yuan to help 240 poverty villages, get involved in the construction of 495 key aided villages, move 1310 households of 25 natural villages, and solve the food and clothing problems of 95,500 absolute poverty population, and promote 139,000 low-income people to increase income and become rich. The General Party Branch of Dumu Village's committee in Dongshan Town, Qinlin District, Qujing, Yunnan, made an overall plan with the coal mining enterprises in the construction of new socialist countryside by combining with the actual local conditions, so that mine villages were in co-construction, new industries were fostered, and poverty villages became rich. A professional grain source cooperative has been established in Dumu Village, in which pooling of land as shares is combined with corporate funding, the guidance of experts hired from the external world is combined with the work of the locally employed female workers, so as to solve the increase income difficulty of rural surplus labors.

\subsection{The co-construction of mine villages promotes the coal mining enterprises in minority areas to better fulfill the social responsibility of driving the prosperity and development of minority areas}

In the co-construction of mine villages, the sense of social responsibility is enhanced within coal mining enterprises, and the enterprises are promoted to give full play to their dominant role, earnestly implement the social responsibilities, intensify helps and supports for the poor, support the public facilities such as schools, hospitals, market and cultural and life venues to the collaborative villages through many ways such as sole proprietorship, joint venture and cooperation, and develop the public welfare undertakings. In this process, multi-channel and multi-form support measures are necessarily taken as much as possible, so as to practically solve the problems such as go-to-school difficulties, go-to-hospital difficulties, get-employed difficulties, transportation difficulties, housing difficulties, cultural activities difficulties, and domestic coal use difficulties, and ultimately create a good development environment for the construction of new countryside.

With the "co-sharing mechanism" for the co-construction of mine villages, the achieved results can be shared in minority areas: benefiting-peasants industries are developed, subsidies to daily life are implemented, public facilities are improved, peasant's income has increased, and the new rural construction is progressive. In recent years, there have been a total of 152 mining enterprises to invest 134 million yuan in building bituminous roads of $120 \mathrm{~km}$ and 41 water conservancy projects. 238 mining enterprises invested 145 million yuan in developing the social undertakings such as education, culture, and health care, among which 54 mining enterprises invested 69.934 million yuan to participate in or independently completed the project construction of 49 schools. Especially, Zhuyuan Xingfa Coking Plant placed a total investment 68 million yuan in the construction of public welfare undertakings from 2003 and another 32.6 million yuan in the construction of the best rural elementary school of Qujing Hemu Elementary School. Laoniupo Coal Mine in Tuozhu Village of Laochuang Town invested 11 million yuan in the construction of Yongkun Elementary School. The coal mining enterprises in Xuanwei invested 500 million yuan in the construction of the public welfare undertakings such as roads, water conservancy projects, and education, thus making the living conditions of the masses around the coal mines greatly improved. Xiangqian Group in Xuanwei invested 10 million yuan to help build a bituminous road of $6.58 \mathrm{~km}$ from Tianba to Xinyue in Lefeng Village, thus solving the transportation difficulties of more than 10000 people (2500 households). Brothers Industrial co., LTD. in Xuanwei Invested 3.18 million yuan to help build 
a bituminous road of $25 \mathrm{~km}$ from Longchang to Gaojiayakou in Longchang Town.

\subsection{The co-construction of mine villages promotes the coal mining enterprises in minority areas to better fulfill the social responsibility of protecting the ecological environment in minority areas}

In the co-construction of mine villages, the overall planning and management of the mineral resources development are enhanced through the environment friendly "co-protection mechanism", the initial development conditions are strictly standardized, the joint responsibilities of enterprises are fully implemented, government and coal mining enterprises are responsible for their own behaviors, and the relationship of the development of resources with conservative utilization and environmental protection is properly handled.

Since 2007 in Fuyuan County, the coal mining enterprises invested a total of 111 million yuan in the ecological construction and environmental governance - the construction of 142 sewage treatment facilities was completed, tree of more than 40000mu was planted, and 72 places with geological hazards were governed, so that the regional environmental and ecological problems are obviously improved. In Housuo Town of Fuyuan County, coal mining enterprises raised 41 million yuan for providing each household with an allowance of 30000 yuan to repair the damaged houses caused by the resource exploitation. In Dage Village of Laochang Town, ecological environment governance was combined with the income increase of the masses, land was transferred using the "company + peasant household" model, coal mining enterprises invested more than 400,000 yuan to focus on the development of the idle land (1700 $\mathrm{mu}$ ), walnut strains (12000), pear strains (11000), and white gourd strains (48000) in two natural villages (Mu'se Village, and Yishude Village). In Qilin District, a mine ecological environment margin system was first implemented in Yunan
Province-1 yuan per a ton of coal is extracted as the fund for governing and controlling the mining area environment. Heap coking and Heap zinc smelting methods and two coal cleaning plants greatly impacting the environment had been banned. Quarries in Mopanshan and Wenjia Ao were ordered to manage the rock collapses; village committees and coal mining enterprises in Dongshan were organized to plant trees of more than 1 million, thus making the vegetation restored and the environment beautified.

\section{Conclusion}

The co-construction of mine villages is a new subject and needs all levels of government and coal mining enterprises in the minority areas to continuously explore in practice. The initial goal of the co-construction must be firmly kept in minds, so as to promote the harmonious development of mining villages based on the concept of "social responsibility". The points of combining with benefits must be firmly maintained, so as to promote the common development of mining villages based on the concept of "mutual benefits". The footholds of every work must be firmly defended, so as to promote the scientific development of mine villages based on the concept of "pragmatic innovation". As a result, new contributions can be made to promoting the sound and rapid development of economy and society in the minority areas.

\section{Acknowledgement}

This paper aided financially by the Advantageous, Special, and Key Subject of the "Twelfth Five-year" Plan of Yunnan Province, "Applied Economics". 


\section{References}

[1] Xiangming ZHANG. Research on the new mechanism for the resources sharing development in mining villages of Qujing $[\mathrm{M}]$. Yunnan People's Publishing House, 2012.

[2] Zhifu GUO. Study on the Scientific exploitation and environmental protection of coal resources [J]. Journal of information science and technology of China, 2007, (20).

[3] Huadong WANG, Yungong XU. The Construction of the Social Responsibility Evaluation System for Coal Mine
Enterprises in Hebei province based on G3 Guidelines [J]. Journal of Hebei Engineering University (Social Science Edition), 2010, (4).

[4] Tianzhou TIAN. The Overall Plan for Mine Villages to Promote the Rural Development [N]. Yunnan Daily, 06-11-2012.

[5] Zhigang CHEN. Co-construction, Co-protection, and Sharing-New Ideas about the New Mechanisms for the Sharing Mineral Resources Development of Mine Villages [J]. Journal of Land and Resources Information, 